\title{
Hypothyroidism-Associated Autoimmune Thyroiditis and Papillary Thyroid Cancer
}

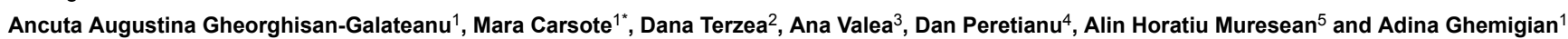 \\ ${ }^{1}$ C.Davila University of Medicine and Pharmacy and C.I.Parhon National Institute of Endocrinology, Bucharest, Romania \\ ${ }^{2}$ Monza Oncoteam Hospital and C.I.Parhon National Institute of Endocrinology, Bucharest, Romania \\ 3.Hatieganu University of Medicine and Pharmacy and Clinical County Hospital, Cluj-Napoca, Romania \\ ${ }^{4}$ SCM Povernei Medical Centre, Bucharest, Romania \\ ${ }^{5}$ St. John Hospital, Bucharest, Romania
}

*Corresponding author: Mara Carsote, C.I.Parhon National Institute of Endocrinology, Bucharest, Romania, Aviatorilor Ave 33-38, Bucharest-011863, Romania, Tel: +40744851934; E-mail: carsote_m@hotmail.com

Received date: Dec 28, 2015, Accepted date: Jan 20, 2016, Publication date: Jan 25, 2016

Copyright: (c) 2016 Gheorghisan-Galateanu AA, et al. This is an open-access article distributed under the terms of the Creative Commons Attribution License, which permits unrestricted use, distribution, and reproduction in any medium, provided the original author and source are credited.

\begin{abstract}
Autoimmune thyroiditis (AI) and differentiated thyroid cancer as papillary type (PTC) are sometimes associated and several common pathogenic mechanisms have been described: BRAF mutations, hOGG1 loss of heterozygosity, interleukin-10 activation, selenoproteomas disturbances. Controversies are related to a more aggressive profile of PTC if Al is presented by interferences with oxidative stress and secondary carcinogenesis.

This is a case report of a 37-year old female diagnosed a decade ago with multi-nodular goiter and hypothyroidism. She was treated in different endocrine centers. She started to accuse intermittent breathing difficulties which were not related to her previous diagnosis of asthma. On admission, the thyroid function was normal under levothyroxine (LT4) therapy with high anti-thyreoperoxidase antibodies levels of $1000 \mathrm{UI} / \mathrm{mL}$ (Normal<35) confirming Al. Thyroid ultrasound showed multiple nodules of 10 millimetres ( $\mathrm{mm}$ ), and a dominant one on the right lobe of $20 \mathrm{~mm}$. Total thyroidectomy and lymph nodes dissection was performed. Pathological report confirmed Al and micro-PTC was identified (of 3 by $2 \mathrm{~mm}$; T1N0M0). The thyroid scintigrame was negative when LT4 substitution was stopped and the blood thyroglobuline (TG) was very low (of $0.2 \mathrm{ng} / \mathrm{mL}$ ) with negative anti-TG antibodies. A good outcome is estimated and no radioiodine ablative therapy was added only TSH suppressive doses of LT4.
\end{abstract}

This case confirms that long standing autoimmune hypothyroidism might not protect of differentiated thyroid cancer but the papillary microcarcinoma display a good prognosis, in this particular situation based on small dimensions of the lesion and low levels of TG after surgery.

Keywords: Thyroid cancer; Autoimmune thyroiditis; Antitireoperoxidase antibodies; Papillary thyroid carcinoma; Hypothyroidism

\section{Introduction}

Thyroid autoimmunity and cancer represents very dynamic yet recent subjects in the field of interdisciplinary approach involving endocrinologists, oncologists, surgeons, gene specialists, as well was pathologists [1-3]. The clinical evaluation starts from the discovery of a thyroid nodule. Generally, asymptomatic thyroid nodules are detected by incidental ultrasound $[4,5]$. Fine needle aspiration is usually useful in nodular or cystic thyroid lesions larger than 10 millimetres $(\mathrm{mm})$ [6]. Many studies agree that there is no significant enlargement during follow-up in most of cases [7]. In small nodes (for instance smaller than $5 \mathrm{~mm}$ ) the cytological report may bring some benefits in cases with changes of the diameters over time [8].

The differentiated thyroid cancer (of papillary and follicular type) associates an increasing frequency in some populations [9]. Whether thyroid autoimmunity represents a risk factor for cancer is still a matter of debate $[10,11]$. Some authors suggest that chronic thyroiditis might protect againts aggressive forms of papillary carcinoma (including BRAF positive patients since the mutation is frequently found in typically papillary forms) [12]. Others suggested that the inflammatory environment induced by the immune process is a trigger for genetic aberrations as seen in hOGG1 loss of heterozygosity (the gene repairs the DNA from free radical-induced oxidative stress) [13]. The theory that oxidative stress is re-settled at a higher level in Hashimoto thyroiditis is mostly known and this may contribute to differentiated cancer progression [14]. Many thyroid microcarcinomas are actually a retrospective diagnosis after surgery despite the fact that patients with chronic thyroiditis generally do not need thyroidectomy [11]. Some studies suggested a more aggressive profile of thyroid cancers in children and young adults diagnosed with autoimmune thyroid disease [14].

Genetic studies revealed a potential connection between autoimmune maladies of the thyroid and cancer. For instance cyclooxygenases (COX) are involved in prostaglandin formation and COX-1 gene is expressed in many tissues including thyroid while COX-2 gene is related to cancer development as seen in skin, mammary gland, stomach, etc. [15]. A recent study on 120 patients showed that COX-2 is related to papillary thyroid cancer but not in 
Citation: Gheorghisan-Galateanu AA, Carsote M, Terzea D, Valea A, et al. (2016) Hypothyroidism-Associated Autoimmune Thyroiditis and Papillary Thyroid Cancer. J Blood Disord Transfus 7: 337. doi:10.4172/2155-9864.1000337

Page 2 of 5

cases underling Hashimoto thyroiditis [15]. COX-2 over-expression has been found also in cytological material collected from people with papillary thyroid carcinoma versus subjects with non-toxic goiter [16]. The detection of p53-antibodies has been linked to the neoplasia since p53 play a distinctive role in cancerous cells growth [17]. It seems that their positive reaction might represent a sign of aggressive behavior and dedifferentiation [18]. The interleukins as key mediators of the immune response may be associated with cell differentiation. In nonanaplasic thyroid carcinoma interleukin-10 (not-18) is probably involved in this process [19].

This paper presents a case from our experience: a young female diagnosed with chronic thyroitidis and treated hypothyroidism presenting an enlarged multi-nodular goiter after years of follow-up. The pathological report confirmed a differentiated thyroid microcarcinoma.

\section{Case Presentation}

\section{Medical history}

A 37-year old smoking female patient has the following medical history. As a child she had asthma (and consecutive therapy was given for a few years), prolapse of mitral valve (which required no therapy). She was diagnosed with multi- nodular goiter a decade ago with normal thyroid function under daily $100 \mu \mathrm{g}$ of levothyroxine (LT4) (Table 1). The serum calcitonin was normal. She was followed up in different endocrine centers. She lived in a non-endemic area regarding the iodine deficiency. In 2015 she accused intermittent breathing difficulties which were not related to her asthma or valve anomalies so she presented to an endocrine check up due to a possible thyroid compression.

\begin{tabular}{|c|c|c|c|c|}
\hline $\begin{array}{l}\text { Hormone/Antibodies } \\
\text { Method of detection }\end{array}$ & Patient's value & Normal limits & Units & Observations \\
\hline \multicolumn{5}{|c|}{ Before total thyroidectomy } \\
\hline $\begin{array}{l}\text { Thyroid stimulating hormone } \\
\text { Chemiluminescence }\end{array}$ & 0.5 & $0.5-4.5$ & $\mu \mathrm{Ul} / \mathrm{mL}$ & \multirow[t]{2}{*}{ under $100 \mu \mathrm{g}$ of LT4/day } \\
\hline $\begin{array}{l}\text { FreeT4 } \\
\text { Chemiluminescence }\end{array}$ & 20.2 & $10.3-24.4$ & $\mathrm{pmol} / \mathrm{L}$ & \\
\hline $\begin{array}{l}\text { Anti-thyreoperoxidase antibodies (TPO) } \\
\text { Chemiluminescence }\end{array}$ & 1000 & $0-35$ & $\mathrm{UI} / \mathrm{mL}$ & \\
\hline $\begin{array}{l}\text { Calcitonin } \\
\text { Chemiluminescence }\end{array}$ & 2.99 & $1-4.8$ & $\mathrm{pg} / \mathrm{mL}$ & \\
\hline $\begin{array}{l}\text { TSH Receptor antibodies (TRAB) } \\
\text { Chemiluminescence }\end{array}$ & 0.3 & $0-1.75$ & $\mathrm{UI} / \mathrm{L}$ & \\
\hline \multicolumn{5}{|c|}{ After total thyroidectomy } \\
\hline $\begin{array}{l}\text { Parathormone (PTH) } \\
\text { Electrochemiluminescence }\end{array}$ & 43 & $15-65$ & $\mathrm{pg} / \mathrm{mL}$ & \\
\hline Thyroid stimulating hormone (TSH) & 60 & $0.5-4.5$ & $\mu \mathrm{Ul} / \mathrm{mL}$ & \multirow[t]{3}{*}{ without LT4 therapy } \\
\hline Free T4 & 3.86 & $10.3-22.4$ & $\mathrm{pmol} / \mathrm{L}$ & \\
\hline Serum thyreoglobulin & 0.2 & $0-10$ & $\mathrm{ng} / \mathrm{mL}$ & \\
\hline Serum anti-thyreoglobulin antibodies (ATG) & 20 & $30-70$ & $\mathrm{UI} / \mathrm{L}$ & \\
\hline Anti-thyreoperoxidase antibodies (TPO) & 255 & $0-35$ & $\mathrm{Ul} / \mathrm{mL}$ & \\
\hline
\end{tabular}

Table 1: The endocrine parameters in a young female presenting Hashimoto thyroiditis and papillary thyroid microcarcinoma (before and after total thyroidectomy).

\section{Endocrine and autoimmune profile}

On admission, the thyroid function was normal under adequate therapy while the thyroid antibodies were extremely high confirming an autoimmune thyroid process (chronic thyroiditis) (Table 1). The thyroid ultrasound showed an enlarged gland associating multiple nodules of maximum 1 centimeter $(\mathrm{cm})$ and a dominant nodule of 2 $\mathrm{cm}$ at the right thyroid lobe with hypo-echoic pattern and increased vascularization.

On the same side, a lymph node of $0.87 \mathrm{~cm}$ was also detected at the medium later-cervical level. Based on recently increased dimensions of the thyroid and thyroid nodules surgery was decided. 
Citation: Gheorghisan-Galateanu AA, Carsote M, Terzea D, Valea A, et al. (2016) Hypothyroidism-Associated Autoimmune Thyroiditis and Papillary Thyroid Cancer. J Blood Disord Transfus 7: 337. doi:10.4172/2155-9864.1000337

Page 3 of 5

\section{Surgical approach and pathological report}

Total thyroidectomy and lymph nodes dissection was recommended and performed. No complication was presented during or after the procedure. The patient started to feel well and she was offered substitution therapy with LT4 to prevent the iatrogenic hypothyroidism. The pathological report confirmed the chronic thyroiditis as a diffuse process with oxyphile areas (Figure 1). A papillary thyroid micro-carcinoma was also identified with small calcifications at the level of right thyroid lobe (Figures $2 \mathrm{~A}$ and 2B). The lesion was of 3 by $2 \mathrm{~mm}$. No lymph node had metastases (T1N0M0). A part from the nodule displaying thyroid cancer the others nodules have adenomatous benign aspects (Figure 3 ).

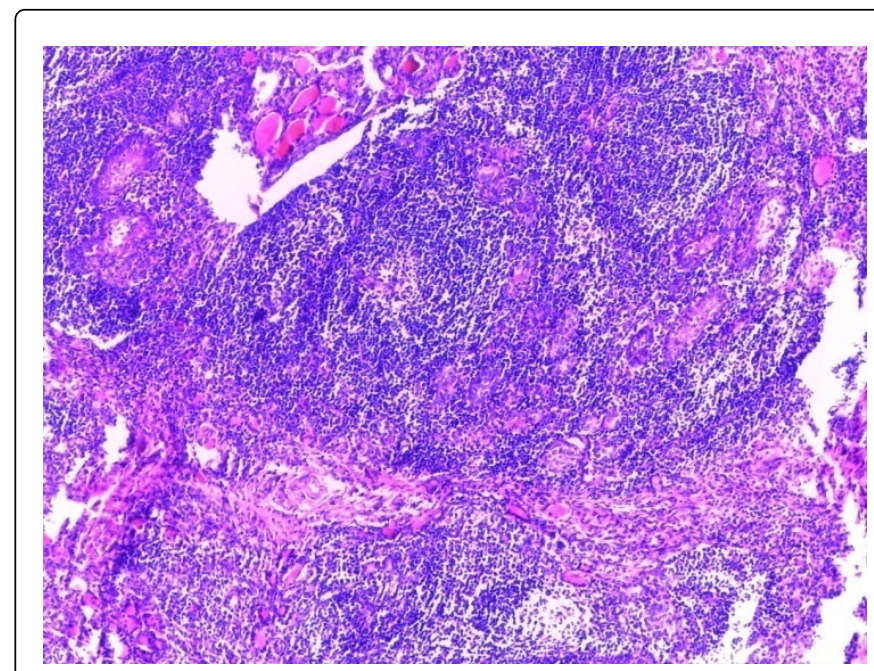

Figure 1: Pathological report: chronic autoimmune thyroiditis: diffuse process with oxyphile areas (hematoxylin-eosin aspect; HE10X).

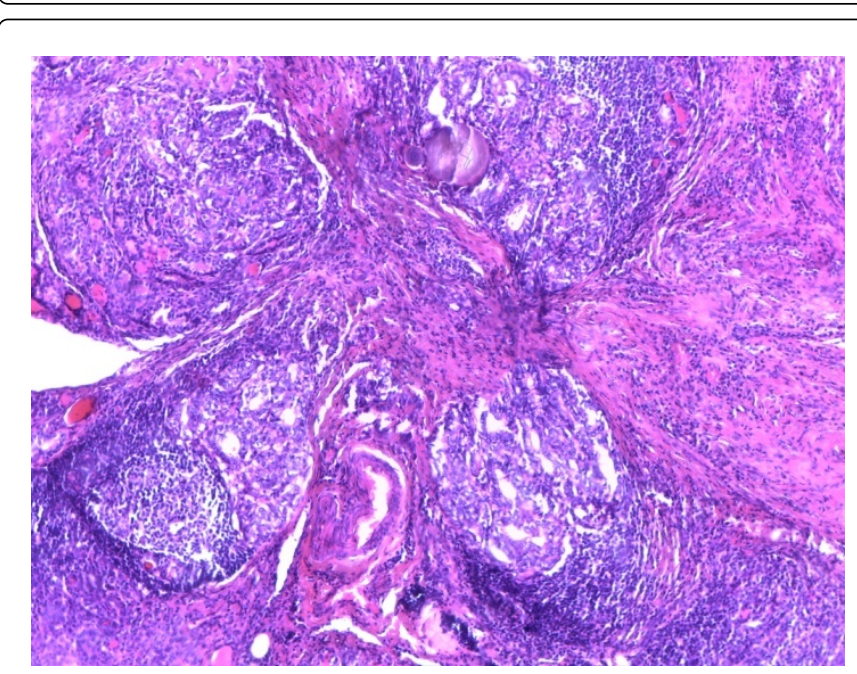

Figure 2A: Pathological report: papillary micro-carcinoma of the thyroid with calcium micro-spheres (hematoxylin-eosin aspect; HE10X).

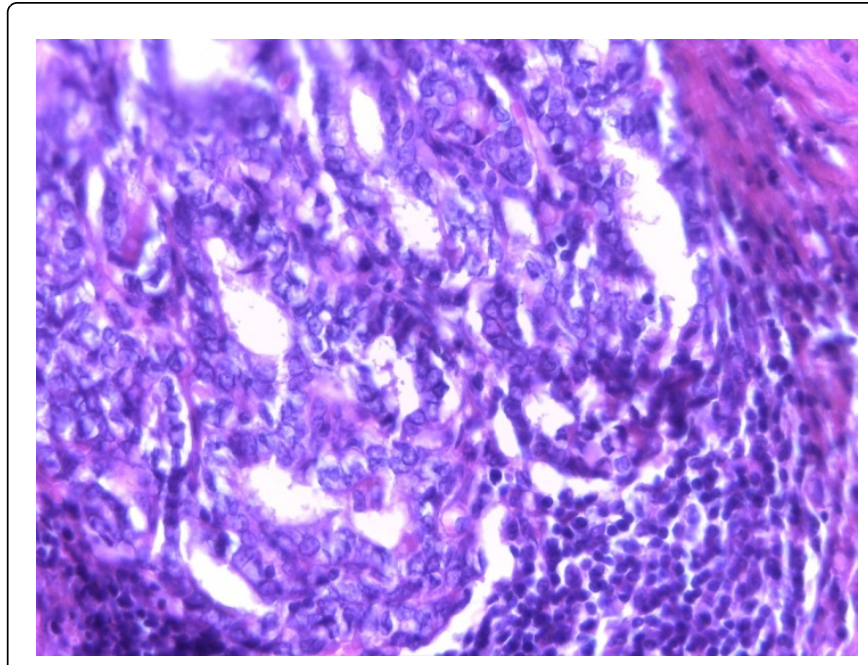

Figure 2B: Pathological report: papillary micro-carcinoma of the thyroid (hematoxylin-eosin aspect; HE40X).

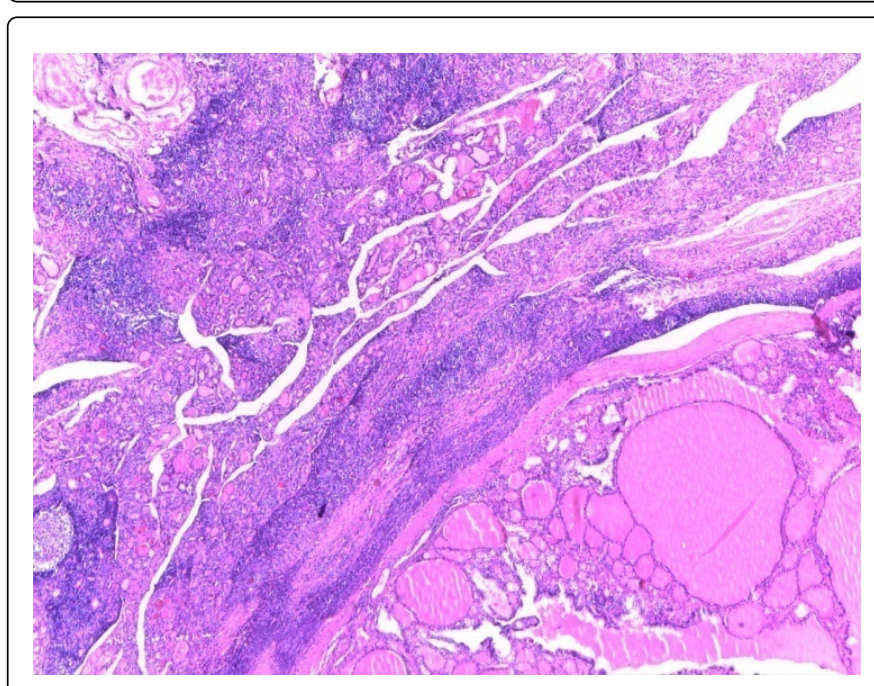

Figure 3: Chronic autoimmune thyroiditis aspects and adenomatous nodules (hematoxylin-eosin aspect; HE 4X).

\section{Follow-up}

After surgery no breathing complains were registered. LT4 therapy was stopped for three weeks to obtain the thyroid scintigrame capture (iodine) which found no residual tissue and the blood levels of thyroglobulin were very low so no supplementary ablation radiotherapy (with 131 radioactive iodine) was considered (Table 1). Daily levothyroxine therapy was further recommended in order not only to substitute the lack of the gland but also to suppress any residual cells. Periodic check-up of TSH and thyroglobulin levels are necessary. A very good prognosis is expected based on pathological report, and potentially on the autoimmune background. 


\section{Discussion}

This case presents an endocrine case from daily practice that a few years ago was considered rare but actually the co-morbidities (differentiated thyroid cancer and Hashimoto thyroiditis) are more frequent that previously appreciated [6]. Recently, the family of selenoproteins has been described in correlation with these two maladies since selenium has one of the highest concentrations in thyroid and the enzymes using it as co-factor are involved in oxidative status, thyroid hormone synthesis, immune modulation and mutagenesis [20-23].

In this particular situation the autoimmune process was confirmed when the patient was re-evaluated for increased dimensions of the goiter with apparently compressive effects. Despite the clinical accuses the autoimmune hypothyroidism was controlled under therapy so no thyroid enlargement could be associated with high TSH. Also the malignant lesion had low dimensions so it could not be correlated with the clinical assessment [6].

The differentiated thyroid cancer is treatable (after total thyroidectomy) with radioiodine ablation but new evidence suggests that in cases with very small lesions (of maximum $5 \mathrm{~mm}$ ) this particular type of treatment is not necessary in correlation with the blood levels of thyroglobulin. However, periodic check up and suppressed levels of TSH (under adequate dosed of daily levothyroxine) are necessary if a thyroid microcarcinoma is found opposite to an entire benign profile after thyroidectomy $[6,11]$. This was the recommended aspects in presented case.

This case also presents autoimmune hypothyroidism; most studies do not correlate the spontaneous levels of TSH with the levels of thyroid antibodies, with the risk of a second autoimmune non-thyroid disorder, neither to the risk of a thyroid malignancy [24-27]. Generally the thyroid function in autoimmune thyroiditis is normal or decreased and hypothyroidism needs LT4 supplementation. A flare-up phenomenon might rarely be seen but this does not change the longterm prognosis [28-30]. A relatively high prevalence of this autoimmune disorder is found but there are still mechanisms incompletely known [28-30]. For diagnosis confirmation the pathological examination (which was possible in our case) is necessary but not routinely recommended since the elevated levels of antithyreoperoxidase antibodies and/or anti-thyreoglobulin antibodies are enough [28-30].

Some subjects with chronic autoimmune thyroid involvement develop papillary thyroid cancer. The specific phenotype is not clear yet but a disturbance in cytokines and immunological profile has been described [31]. Also, a second autoimmune condition as systemic sclerosis (in addition to AI) might increase the risk of papillary thyroid cancer, based on a study published in 2015 including 327 unselected cases of systemic sclerosis [32]. In our particular case, the immune environment is suggested by asthma and AI but limited data are known about the respiratory malady and AI-associated PTC [33]. A study on 322 subjects who underwent fine needle aspiration was consistent with the correlation between chronic autoimmune thyroid conditions and positive cytology for malignancy and the entire immune thyroid spectrum was included: AI with abnormal circulating anti-thyroglobulin antibodies and Graves's diseases [34]. The female case we described had the serologic confirmation of AI based only on antithyreoperoxidase antibodies and not on thyroglobulin antibodies while the TSH-receptor antibodies were negative (infirming Basedow disease). During the last years the evidence based medicine provided enough amounts of data proving that both conditions involve common genetic susceptibility and chemokines pathways [10,35].

As limits of our study we mention the lack of genetic tests involving the two maladies but none of these is a routinely recommended by current guidelines for differentiated thyroid carcinoma.

\section{Conclusion}

The papillary type of differentiated thyroid cancer is associated with different factors of risk; among them chronic autoimmune thyroiditis is correlated with a more aggressive profile according to some studies and new data suggest common pathogenic pathways regarding the immune response and the disturbances of oxidative stress as triggers for oncogenesis. This adult female subject case confirms that long standing autoimmune hypothyroidism might not protect against differentiated thyroid cancer but the papillary microcarcinoma display a good prognosis.

\section{Acknowledgement}

We thank each member of the medical teams and the patient.

\section{References}

1. Fiore E, Latrofa F, Vitti P (2015) Iodine, thyroid autoimmunity and cancer. Eur Thyroid J 4: 26-35.

2. Omur O, Baran Y (2014) An update on molecular biology of thyroid cancers. Crit Rev Oncol Hematol 90: 233-252.

3. Chruscik A, Lam AK (2015) Clinical pathological impacts of microRNAs in papillary thyroid carcinoma: microRNAs in papillary thyroid carcinoma: A crucial review. Experimental and Molecular Pathology 99: 393-398.

4. Quianzon CC, Schroeder PR (2015) Initial evaluation of thyroid nodules by primary care physicians and internal medicine residents. J Community Hosp Intern Med Perspect 5: 27192.

5. Brito JP, Castro MR, Dean DS, Fatourechi V, Stan M (2015) Survey of current approaches to non-diagnostic fine-needle aspiration from solid thyroid nodules. Endocrine 49: 745-751.

6. Haugen BR, Alexander EK, Bible KC, Doherty G, Mandel SJ, et al. (2016) 2015 American Thyroid Association Management Guidelines for Adult Patients with Thyroid Nodules and Differentiated Thyroid Cancer. Thyroid 26: 1-133.

7. Durante C, Costante G, Lucisano G, Bruno R, Meringolo D, et al. (2015) The natural history of benign thyroid nodules. JAMA 313: 926-935.

8. Moon HJ, Lee HS, Kim EK, Ko SY, Seo JY, et al. (2015) Thyroid nodules â $\%_{0}$, $5 \mathrm{~mm}$ on ultrasonography: are they "leave me alone" lesions? Endocrine 49: 735-744.

9. Petrulea MS, Plantinga TS, Smit JW, Georgescu CE, Netea-Maier RT (2015) PI3K/Akt/mTOR: A promising therapeutic target for nonmedullary thyroid carcinoma. Cancer Treat Rev 41: 707-713.

10. Antonelli A, Ferrari SM, Corrado A, Di Domenicantonio A, Fallahi P (2015) Autoimmune thyroid disorders. Autoimmun Rev 14: 174-180.

11. Nguyen C, Wang M (2014) Practice patterns in the surgical treatment of papillary thyroid microcarcinoma. Thyroid 24: 1816-1817.

12. Kim SK, Woo JW, Lee JH, Park I, Choe JH, et al. (2016) Chronic lymphocytic thyroiditis and BRAF V600E in papillary thyroid carcinoma. Endocr Relat Cancer 23: 27-34.

13. Royer MC, Zhang H, Fan CY, Kokoska MS (2010) Genetic alterations in papillary thyroid carcinoma and hashimoto thyroiditis: An analysis of hOGG1 loss of heterozygosity. Arch Otolaryngol Head Neck Surg 136: 240-242.

14. Iliadou PK, Effraimidis G, Konstantinos M, Grigorios P, Mitsakis P, et al. (2015) Chronic lymphocytic thyroiditis is associated with invasive 
Citation: Gheorghisan-Galateanu AA, Carsote M, Terzea D, Valea A, et al. (2016) Hypothyroidism-Associated Autoimmune Thyroiditis and Papillary Thyroid Cancer. J Blood Disord Transfus 7: 337. doi:10.4172/2155-9864.1000337

Page 5 of 5

characteristics of differentiated thyroid carcinoma in children and adolescents. Eur J Endocrinol 173: 827-833.

15. Krawczyk-Rusiecka K, Wojciechowska-Durczynska K, Cyniak-Magierska A, Zygmunt A, Lewinski A (2014) Assessment of cyclooxygenase-1 and 2 gene expression levels in chronic autoimmune thyroiditis, papillary thyroid carcinoma and nontoxic nodular goitre. Thyroid Res 7: 10.

16. Krawczyk-Rusiecka K, Wojciechowska-Durczynska K, Cyniak-Magierska A, Adamczewski Z, Galecka E, et al. (2011) COX-2 expression in papillary thyroid carcinoma (PTC) in cytological material obtained by fine needle aspiration biopsy (FNAB). Thyroid Res 4: 3.

17. Pan P, Han X, Li F, Fu Q, Gao X, et al. (2014) Detection of serum p53 antibodies from Chinese patients with papillary thyroid carcinoma using phage-SP-ELISA: correlation with clinical parameters. Endocrine 47: 543-549.

18. Hasbek Z, Turgut B, Erselcan T (2014) p53 antibody: is it an indicator of dedifferentiated thyroid cancer? Ann Nucl Med 28: 42-46.

19. Cunha LL, Tincani AJ, Assumpção LV, Soares FA, Vassallo J, et al. (2011) Interleukin-10 but not interleukin-18 may be associated with the immune response against well-differentiatedthyroid cancer. Clinics (Sao Paulo) 66 1203-1208.

20. Gupta S, Jaworska-Bieniek K, Lubinski J, Jakubowska A (2013) Can selenium be a modifier of cancer risk in CHEK2 mutation carriers? Mutagenesis 28: 625-629.

21. Lacka K, Szeliga A (2015) Significance of selenium in thyroid physiology and pathology. Pol Merkur Lekarski 38: 348-353.

22. Papp LV, Holmgren A, Khanna KK (2010) Selenium and selenoproteins in health and disease. Antioxid Redox Signal 12: 793-795.

23. Santos LR, Durães C, Mendes A, Prazeres H, Alvelos MI, et al. (2014) A polymorphism in the promoter region of the selenoprotein $S$ gene (SEPS1) contributes to Hashimoto's thyroiditis susceptibility. J Clin Endocrinol Metab 99: E719-723.

24. Gheorghisan-Galateanu AA, Carsote M, Terzea D, Paun D, Poiana C (2015) Premature ovarian failure and thyroid anomalies in patients with autoimmune disturbances. Gineco.eu Journal 11: 53-55.
25. Peretianu D, Carsote M, Poiana C, Staicu DC, Aninisi I, et al. (2015) Immune Associations in Hashimoto Thyroidithis and Related Disorderdes. Internal Medicine 4: 7-45.

26. Paun DL, Petris R, Carsote M, Ferechide D, Poiana C (2013) Particular aspects in autoimmune thyroid diseases. Practica Medicala VIII/3: 173-177.

27. Yi JW, Park JY, Sung JY, Kwak SH, Yu J, et al. (2015) Genomic evidence of reactive oxygen species elevation in papillary thyroid carcinoma with Hashimoto thyroiditis. Endocr J 62: 857-77.

28. Thomas T, Sreedharan S, Khadilkar UN, Deviprasad D, Kamath MP, et al. (2014) Clinical, biochemical \& cytomorphologic study on Hashimoto's thyroiditis. Indian J Med Res 140: 729-735.

29. $\mathrm{Li} \mathrm{H}, \mathrm{Li} \mathrm{J}$ (2015) Thyroid disorders in women. Minerva Med 106: 109-114.

30. Ajjan RA, Weetman AP (2015) The Pathogenesis of Hashimoto's Thyroiditis: Further Developments in our Understanding. Horm Metab Res 47: 702-710.

31. Zivancevic-Simonovic S, Mihaljevic O, Majstorovic I, Popovic S, Markovic S, et al. (2015) Cytokine production in patients with papillary thyroid cancer and associated autoimmune Hashimoto thyroiditis. Cancer Immunol Immunother 64: 1011-1019.

32. Antonelli A, Ferri C, Ferrari SM, Di Domenicantonio A, Giuggioli D, et al. (2015) Increased risk of papillary thyroid cancer in systemic sclerosis associated with autoimmune thyroiditis. Rheumatology (Oxford): kev358.

33. Weldon D (2005) Endocrinological masqueraders of allergy. Allergy Asthma Proc 26: 440-444.

34. Hadjisavva IS, Dina R, Talias MA, Economides PA (2015) Prevalence of Cancer in Patients with Thyroid Nodules in the Island of Cyprus: Predictive Value of Ultrasound Features and Thyroid Autoimmune Status. Eur Thyroid J 4: 123-128.

35. Mikos> H, Mikos M, Obara-Moszynska M, Niedziela M (2014) The role of the immune system and cytokines involved in the pathogenesis of autoimmune thyroid disease (AITD). Endokrynol Pol 65: 150-155. 